EDUCATIONAL

RESOURCE

Volume 12 Issue 32020

DOI: 10.21315/eimj2020.12.3.7

ARTICLE INFO

Submitted: 04-05-2020

Accepted: 20-05-2020

Online: $30-09-2020$

\section{Online Small Group Clinical Be(side) Teaching (BeST) Using Authentic Scenario with Hypothetico-Deductive Approach and Gagne Instructional Model}

\author{
Shahid Hassan', Hasnain Baloch² \\ ${ }^{1}$ Surgery School of Medicine, International Medical University, Bukit \\ Falil, Kuala Lumpur, MALAYSIA \\ ${ }^{2}$ LLearning, Learning Resources Department, International Medical \\ University, Bukit falil, Kuala Lumpur, MALAYSIA
}

To cite this article: Hassan $S$, Baloch $H$. Online small group clinical be(side) teaching (BeST) using authentic scenario with hypothetico-deductive approach and Gagne instructional model. Education in Medicine Journal. 2020;12(3):55-64. https://doi.org/10.21315/eimj2020.12.3.7

To link to this article: https://doi.org/10.21315/eimj2020.12.3.7

\begin{abstract}
Online training is intended to provide a solution to on-campus teaching and learning, this is not always the case. The important factor in designing online learning sessions should be consider, how to prevent students from getting frustrated with increasingly high workload. The basic principle to ensure this is to divide a session into several chunks that help students being engaged and motivated. One should think of putting up something, which is collaborative, interactive, dynamic and full of fun. Bedside Teaching (BST) of a clinical environment converted to an online delivery however, achieving learning outcome, is difficult to imagine. In the current scenario of COVID-19 pandemic, it is wise to consider educational pedagogy to design and develop teaching and learning method rather than focusing on using technology for online delivery. Teachers can be guided by the nine steps of Gagne's Instructions Model that authors have explored and named Be(Side) Teaching (BeST) as a traditional BST. The method is a systematic process for instructional classes in which each step addresses a form of communication that help learning process online. On completing each step learners are likely to be engaged that may help them to retain and transfer information for longer retention with a contextualised Kolb experiential learning cycle at the end. Authors adapted clinical reasoning in a problem-solving learning method using small group (6-8 students) guided by a supervisor. The learning experience design worked well in supervisor's experience.
\end{abstract}

Keywords: Bedside teaching, Online clinical teaching, COVID-19, Experiential learning, Gagne's instructional model

CORRESPONDING AUTHOR

Professor Shahid Hassan, Surgery School of Medicine, International Medical University, 57000 Bukit Jalil, Kuala Lumpur, Malaysia | Email: shahidhassan@imu.edu.my

\section{INTRODUCTION}

Bedside Teaching (BST) during the era of 1960 s was estimated to be representing as much as $75 \%$ of all clinical training (1). However, the classroom teaching has been on the increase ever since and the current estimates for BST has been found to vary from $15 \%-25 \%$ (2). Medicine is learned by the bedside and not in the classroom' are quotes of the famous Sir William Osler (3). BST besides engaging students in analytic 
reasoning in clinical education also provide opportunities to learn professionalism by observing role model teachers and clinical supervisors in clinical environment. It has been established that a thorough medical interview and physical examination have been shown to help in correct diagnosis in not less than $73 \%-90 \%$ of cases in clinical practice (4). However, to conduct BST no standard format is followed and often it leads to students' frustrations, which are taken through this most important clinical skills learning with no uniformly observed method. This might have been the reason why BST became gradually less popular with clinical teachers in their in-patient training opportunities. To save students from confusion, some excellent work on BST protocols came from a number of authors including Peyton (5), Alguire et al. (6), Dent and Harden (7), and Rubenstein and Talbot (8). A recent desperate situation emerging from COVID-19 made it even worst and almost impossible to imagine BST, while observing social distancing and closely monitored in-ward clinical teaching allowed by hospitals in Malaysia. Authors took this opportunity to design and develop online BST using educational pedagogy of a number of philosophical approaches and technology combined together. The method evolved may not provide the physical feel of shared space and patient but may compliment face-to-face BST in many ways.

In the current scenario of COVID-19 pandemic, it is not wise to rely solely on technology. The BST of a clinical environment converted to online delivery can still be achieved. One may assume that faculty and students may be facing issues related to network connectivity, bandwidth, delay in response, devices connectivity and applications access. In a recent survey by Malaysian Communications and Multimedia Commission (MCMC) in Malaysia, it has been established that Wi-Fi utility has been reduced from $55.9 \%$ in 2016 to $36.3 \%$ in 2018 . Students prefer their own mobile internet data plan rather than relying on free Wi-Fi (9). Designing and developing content, learning activities and assessment for BST to an online mode of delivery, supervisors can be guided by the nine steps of Gagne's Instructions Model (10) that has helped authors to developed current model of online BST, authors named this model as a $\mathrm{Be}$ (Side) Teaching (BeST). The model is a systemic process for instructional classes in which each step addresses a form of communication that help learning process online. On completing each step learners are likely to be engaged that may help them to retain and transfer information into long term memory with a contextualised Kolb experiential learning cycle (11) at the end.

Although online teaching is intended to provide a solution to on-campus learning, this is not always the case. We observed that during COVID-19, teaching faculty often converts their face-to-face (F2F) material into an online digital material that simply is an e-reading task for students than an interactive learning experience especially when it is followed by unrealistic summative assessment. The important factors in designing e-learning sessions are to prevent students from getting frustrated with increasingly high workload. Think of putting up something, which is collaborative, interactive, dynamic and full of fun (12). The fun in on-learning could be having more interaction with think aloud approach proposing question and inquiries in clerking patient online, watching videos of authentic cases from supervisor's archive or other educational resources with more visual impact about the case. The session could be recorded for students to watch as many times as they want. A good priority to set an online session will be to review the learning outcome of one's F2F session and to align it with online courses keeping with institution and programme learning outcome.

The basic principle to ensure this will be, to divide a session into several chunks that keep students engagement and motivation (13). Besides some advantages, online courses have their limitations particularly in the domain of clinical teaching. Interviewing directly versus interviewing through an 
interface such as using phone/virtual/ web-conferencing/social media may lack human touch, feelings and expression of non-verbal communications. However, a clinical scenario may differ in terms of presentation, approach, clinical signs and even management if it is not derived from an authentic case. In clinical teaching online, the students main frustrated is the lack of human contact, the absence of an interactively involved teacher and an inability to have discussion with their peer. A teacher in supervisor, coach, mentor or facilitator and if needed in several other roles like acquiring a simulated patient roleplay replacing a student encounter with a patient of a real world can provide a solution to this. This act of a teacher should continue even after the session with a personal interaction, which is essential for students to rely on a teacher they can contact if they want to.

Literature has established that the best way to learn is to practice it as the famous learning by doing concept (14). It is only by practicing that learner can internalised and recalled the content and skills which refers to the concept of experiential learning. This may be another limitation, however, without compromising the clinical teaching in a restricted COVID-19 environment. Online forced learning provides a good opportunity to discuss students about how best an adult can learn. It is time to promote learning skills rather than switching over and uploading material online, albeit slide sharing or voiceover-slide presentation that remove the teacher from the scene. Many online courses overlook this fact and solely rely on theoretical content uploaded on portal. This deprived students from handson practice and the learning process does not achieve the learning outcome.

Our effort should be to organise quality online sessions that keep students motivated with interesting content, its delivery strategy and a communication campaign that create metacognitive awareness with perception of learning principles among them. In the given scenario of COVID-19 pandemic and limitation of movements, it is teacher's duty to offer the best to the students and not a mediocre learning session online to replace a F2F on-campus sessions that students have been so used to it. Prioritise teaching and learning by designing the best session and not simply following what the technology dictates. It becomes even worst if the teachers or the students are not the competent users of those tools and will simply be carried away with technology.

Another priority to set is to review the learning outcome of your F2F courses to align it with online courses keeping with institution and programme learning outcome. The best way to solve this problem is to plan well your session before launching them. Choose the materials that will complement the curriculum goals. Set the measurable indicators before launching the online sessions and look for its impact on curriculum and institution. Design assessment that does not increase students' workload rather follows the principles of assessment that is assessment for learning and assessment on learning. Focus should be on formative assessment and a reflective practice provided with a semi-structured feedback model (15). Never forget to ask for the feedback else, you would never know how successful your session went online.

\section{PLANNING AND DELIVERY METHOD}

\section{Learning Approach Adapted in Online BST}

Authors propose clinical reasoning in a problem-solving learning method, which is an extension of problem-based learning approach using small group guided by a supervisor. The method is both, an adaptation of Barrows' hypotheticodeductive approach (16) and an application of Kassirer's iterative hypothesis testing with thinking-aloud procedure (17). Supervisor in proposed method can take initiative to identify a real scenario case from his/her archive of clinical practice or find a relevant case from online authentic resources. 
Supervisor will be responsible for making e-portfolio and holds all the information about the case.

Supervisor in proposed method starts the session after greeting everyone online and introduces the patient's clinical problem only as his chief complaint. Supervisor at this stage takes the dual role of a supervisor as well as the patient. Next, he/she invites the questions to interview the patient to explore information from the history. The supervisor as an information holder will reveal the information upon request, which is justified by an individual student or entire group with rationale. The group work through the clinical problem using an iterative approach, which is performed in the same way a clinician investigates a patient problem. Having exhausted with all the likely questions by individual or the group, supervisor gives summary based on history of the patient and then invites students to generate the hypothesis in terms of listing down the differential diagnosis. Whatever the group put forward is written down by the supervisor using the white board feature of any online collaborative tool used to run this session. The similar process is repeated for physical examination and investigations, and the end of each clinical attribute the hypothesis generated by the group is reviewed in line with further information sought to retain or delete some of those differential diagnoses in a typical hypothetico-deductive approach with speak a loud process of entire members in the group. From the student's narrative feedback, we conclude that this is a very stimulating method in triggering students' analytic reasoning in a similar way they experience in authentic BST. It is expected that this process will provide students an opportunity to practice the clinical reasoning process.

\section{Instructional Model}

The Gagne's Instructional Model was followed to develop current BeST online teaching. By applying this model, the first thing to do is to identify an authentic (real) case relevant with the theme of the posting week. It would be better to divide the whole session into small chunks and to design and develop the teaching material appropriate for online teaching (document/multimedia presentation). Authors preferred PowerPoint slide presentation that must be delivered in a live slide show rather than a voice over recorded PowerPoint. This is because in doing so, it might kill the purpose of BST modified concept that needs a teacher in supervisor role as well as a patient roleplay during the session. Gagne's 9-events is applied to current model in the process of learning (Figure 1).

\section{Step 1: Gaining attention (reception)}

The first way to gain students attention is via instant messaging application through the group leader and assuring them BST can still be delivered. However, in a modified way by developing 5-7 slides for online presentation (Figure 2) about the principles of experiential learning cycle of a contextualised learning experience can be incorporated with online presentation. 


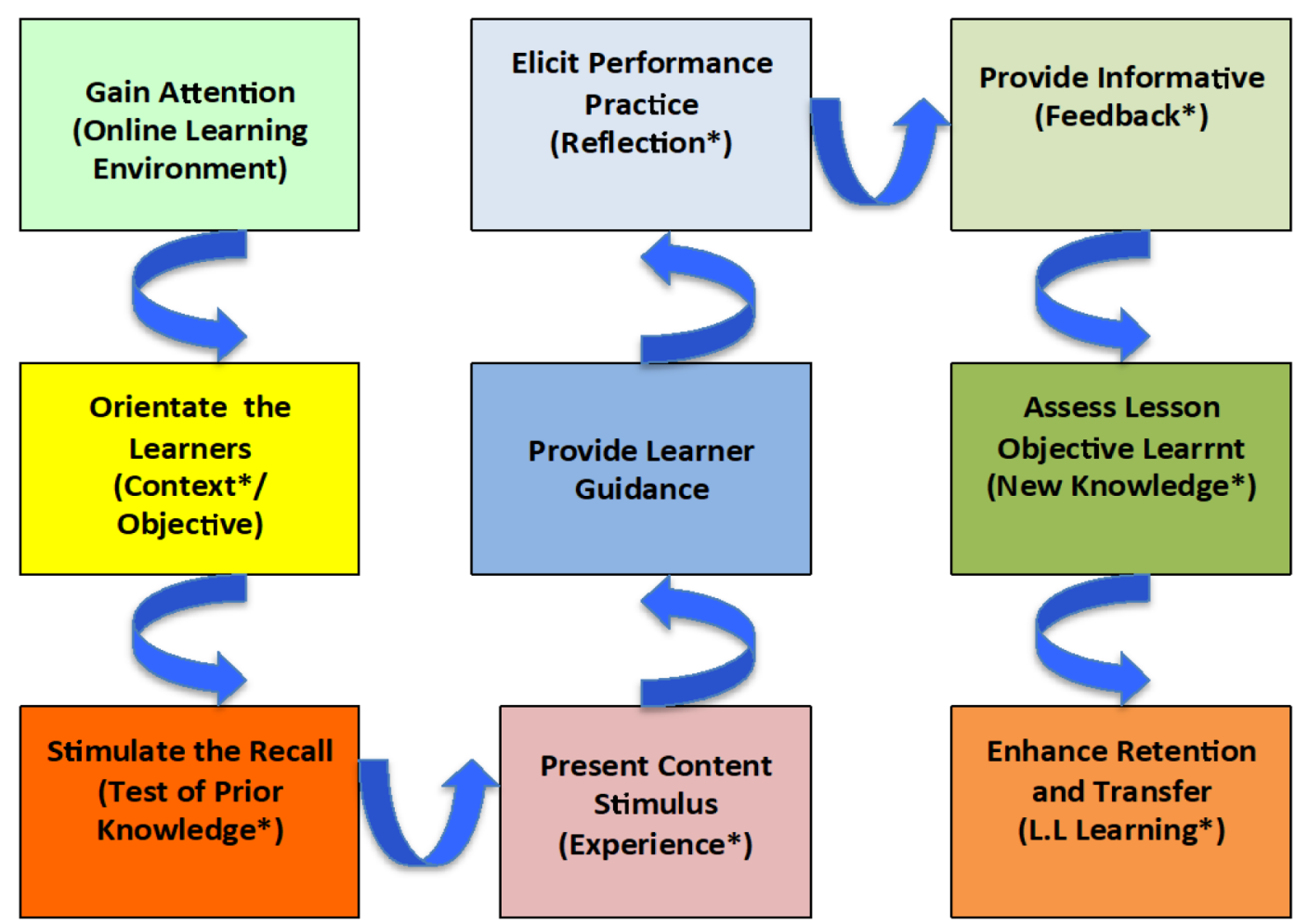

Figure 1: Gagne 9-event of instructions synchronised with experiential cycle*.

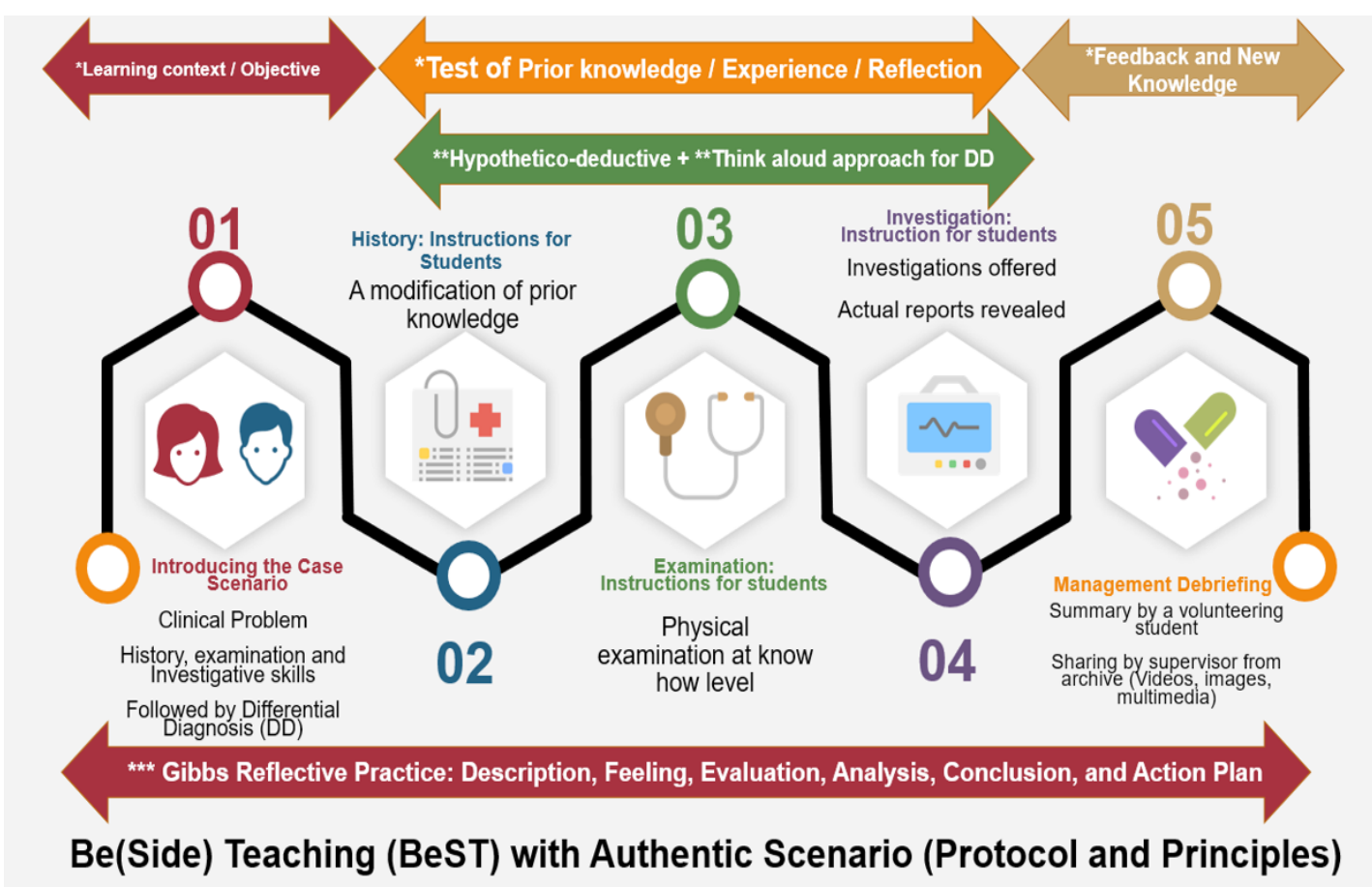

Figure 2: The conceptual model for ${ }^{*}$ Principles of Experiential Learning, ${ }^{* *}$ Hypothetico-deductive and think aloud approach, ${ }^{* * *}$ Gibbs Reflective Practice with online delivery (steps 1-5 modified from Gagne model) of BeST. 


\section{Step 2: Informing learners of the objectives (expectancy)}

This step required to review $\mathrm{F} 2 \mathrm{~F}$ delivery learning outcome to readjust the process (see Table 1). However, it will be realistic to keeping with compromises made in delivering BeST compared to a real time BST. It is exactly in a similar spirit of clinical skills lab teaching, which is used to complement real BST.

Table 1: Learning outcome of authentic BST versus online BeST using technology

\begin{tabular}{|c|c|c|}
\hline No. & Learning outcome for BST: In-routine & Learning outcome for BeST: On-line \\
\hline 1. & $\begin{array}{l}\text { Identify preferably a relevant patient fit to } \\
\text { theme of the week posting from the ward. }\end{array}$ & $\begin{array}{l}\text { Identify the clinical problem of an authentic case } \\
\text { presented to the entire group by the supervisor, } \\
\text { who also role-plays as patient. }\end{array}$ \\
\hline 2. & $\begin{array}{l}\text { Apply the clerking skills and experience the } \\
\text { patient work up based your prior knowledge. }\end{array}$ & $\begin{array}{l}\text { Develop your questions relevant for each clinical } \\
\text { attributes of history taking, physical examination, } \\
\text { to supervisor role-playing as patient. }\end{array}$ \\
\hline 3. & $\begin{array}{l}\text { Demonstrate and reflect on your experience } \\
\text { by presenting the case to supervisor and rest } \\
\text { of your group mates. }\end{array}$ & $\begin{array}{l}\text { List down the differential diagnosis after } \\
\text { completing the history questions and response } \\
\text { from the patient and later review the } D / D \text { in a } \\
\text { deductive manner to remove those not relevant. }\end{array}$ \\
\hline 4. & $\begin{array}{l}\text { Analyse the feedback from the supervisor and } \\
\text { respective colleagues to identify the gaps in } \\
\text { knowledge and skills. }\end{array}$ & $\begin{array}{l}\text { Recall the relevant investigations that help in } \\
\text { diagnosis and suggest the outline of a therapeutic } \\
\text { management for the patient. }\end{array}$ \\
\hline 5. & $\begin{array}{l}\text { Develop new knowledge by further } \\
\text { continuing learning in the areas identified the } \\
\text { feedback you received. }\end{array}$ & $\begin{array}{l}\text { Identify gaps in knowledge from the supervisor's } \\
\text { debriefing relevant to case and continue learning } \\
\text { to develop new knowledge. }\end{array}$ \\
\hline
\end{tabular}

\section{Step 3: Stimulating recall of prior learning (retrieval)}

Hypothetico-deductive and think a loud approach can be used to engage every student in the session to participate by asking questions from each of the clinical attributes divided into small chunks. This is followed by a critical thinking process in a collaborative manner to list down the likely differential diagnosis by the group. In the next four steps of model delivery, the supervisor takes the role of a patient, which students can ask questions like they would do in their clerking exercise in real situation (BST).

\section{Step 4: Presenting the stimulus (selective perception)}

This part of the session goes on to cover history taking, physical examination and investigations that students will practice to generate and organise the hypothesis. Ultimately students can be invited to suggest the outline of therapeutic management. However, after each of these clinical attributes, a step back is taken by the student to review the differential diagnosis after the first clinical attribute of history taking onward to investigation.

\section{Step 5: Providing learning guidance (semantic encoding)}

In this step, two sets of slides one on how best an adult can learn (principles of learning) adapting Gibbs experiential cycle (Figure 1) and another set of slides on protocol to deliver current model (Figure 2) are also part of this method and delivered on an exclusive and mutually agreed time. In this session, semantic encoding is done by using multimedia, including authentic patient's scenario and related videos, pictures, lab and investigations report to 
create contextualised learning for long term retention of learning experience.

\section{Step 6: Eliciting performance (responding)}

Students response is practiced by asking students to apply their critical high order thinking with analytic reasoning to list down the differential diagnosis after each clinical attribute. This is to enforce the Robert Gagne's concept of online teaching using technology but in smaller chunks and moving forward with assurance that learning is taking place (Figure 2, steps 1-5). Once the session is over, students can access video recording and demonstrate the psychomotor skills shown at "know how" level by roleplaying with available siblings or other family members.

\section{Step 7: Providing feedback (reinforcement)}

Feedback is important for any instructional learning model. This can be done with an immediate and a long-term impact. Immediate impact comes from the supervisor by a debriefing on the case discussed by taking them through the teaching material (pictures, short videos of operative procedures and lab reports) supported with supervisor's own archive or from online resources, keeping with copyright and patients' privacy and confidentiality as debriefing. For this part, a feedback survey is developed for students to give their feedback (Table 2).

Table 2: Reflection of my experience on attending online BeST

\begin{tabular}{|c|c|c|}
\hline No. & Steps of Gibbs Reflective Cycle & My Reflection \\
\hline 1. & Description (What was the event?) & \\
\hline 2. & Feeling (What is my feeling after attending this session?) & \\
\hline 3. & $\begin{array}{l}\text { Evaluation (What was good or bad that I experienced after } \\
\text { attending this session?) }\end{array}$ & \\
\hline 4. & $\begin{array}{l}\text { Analysis (Was it sufficient or what else can I expect of } \\
\text { online BST during restricted movement control order due to } \\
\text { COVID-19?) }\end{array}$ & \\
\hline 5. & $\begin{array}{l}\text { Conclusion (Did I achieve the intended learning outcome } \\
\text { provided for this innovative online BST?) }\end{array}$ & \\
\hline 6. & $\begin{array}{l}\text { Action Plan (Do I need more such sessions and how best I } \\
\text { can make use of it?) }\end{array}$ & \\
\hline
\end{tabular}

\section{Steps 8 and 9: Assessing performance and enhancing retention transfer}

Assessment of performance may not be that difficult in a situation where students are already trained to have reflective practice. A semi-structured form based on Gibbs reflective cycle to reflect on their experience (Table 3) of a modified online version of
BST. This can be assessed through an end of posting assessment using multiple choice question (MCQ) (one best answer/ extended matching question (OBA/EMQ) or structured essay question (SEQ) or both to evaluate their retention and transfer of knowledge applied to a test situation of similar or different but relevant to the theme of clinical posting. 
Table 3: Feedback from the students on problems associated with on-line experience of BeST

\begin{tabular}{|c|c|c|c|c|c|c|c|}
\hline \multicolumn{8}{|c|}{$\begin{array}{l}\text { Feedback: Online Small Group BST Using Authentic Scenario and Case Discussion Method } \\
\text { Supervisor's Name/Department }\end{array}$} \\
\hline No. & $\begin{array}{l}\text { Clinical posting cohort } \\
\text { student's name }\end{array}$ & $\begin{array}{c}\text { Problems with } \\
\text { connectivity } \\
\text { A lot }=1 \\
\text { Some }=2 \\
\text { No }=3\end{array}$ & $\begin{array}{c}\text { Problem with } \\
\text { audio experience } \\
\text { A lot }=1 \\
\text { Some }=2 \\
\text { No }=3\end{array}$ & $\begin{array}{c}\text { Problem with } \\
\text { slide shared } \\
\text { A lot }=1 \\
\text { Some }=2 \\
\text { No }=3\end{array}$ & $\begin{array}{c}\text { Problem in } \\
\text { watching video } \\
\text { A lot }=1 \\
\text { Some }=2 \\
\text { No }=3\end{array}$ & $\begin{array}{c}\text { Problem } \\
\text { in activity } \\
\text { performed } \\
\text { A lot }=1 \\
\text { Some }=2 \\
\text { No }=3\end{array}$ & $\begin{array}{c}\text { Learning outcome } \\
\text { (posted in advance) } \\
\text { Not achieved = } 1 \\
\text { Partly achieved = } 2 \\
\text { Achieved = } 3\end{array}$ \\
\hline
\end{tabular}

1.

2.

3.

Any comment to improve the

$$
\text { methods }
$$

Note: "Activities performed refer to use of associated functions of online web conferencing tool's feature white board (active writing), audience engagement tool, mathematical equation tool, hands-on with spread sheet/statistical analysis tools or other likewise accessories. 


\section{CONCLUSION}

In students' perspective online world, no matter how facilitating it can still be frustrating. Learners often need physical space and authentic learning environment to have a feel of real tools (simulations, patients and clinical skills lab facilities). The BST converted to an online delivery is difficult to imagine. However, careful and well estimated outcome of clinical teaching online can be organised to complement authentic BST in a F2F learning environment. How technology can facilitate the transformation of learning outcomes will depend on how we make the use of learning theories to design and develop learning activities. However, it is important for students and teacher to understand the pedagogy before selecting the technology. Learning theory can help to explain the educational potential of technology. BeST though compliment BST, however, have some limitations mentioned above can be addressed by enhancing the content, interactivities and adding simulation elements in conducting and delivering this method.

$\mathrm{BeST}$ is an online version of BST has been designed and developed in a desperate situation due to COVID-19 by carefully analysing and putting together of Barrow's and Kassirer's hypothetico-deductive and think aloud approaches to learning. Further using nine steps Gagne's instructional model in an experiential learning experience of Kolb's model helped authors to think of continuing clinical teaching with student's engagement to achieving the learning outcome of a BST in a modified way though.

\section{ACKNOWLEDGEMENTS}

Authors would like to extend their thanks to the Department of Surgery, School of Medicine at International Medical University for allowing to innovatively redesigning clinical teaching. We would also like to thank to the School of Medicine, Universiti Sains Malaysia for authentic clinical case materials retrieved from the clinical practice there.

\section{REFERENCES}

1. Crumlish CM, Yialamas MA, McMahon GT. Quantification of bedside teaching by an academic hospitalist group. J Hosp Med. 2009;4:304-7. https://doi.org/10.1002/ jhm. 540

2. Beigzadeh A, Adibi P, Bahaadinbeigy K, Yamani N. Strategies for teaching in clinical rounds: a systematic review of the literature. Journal of Research in Medical. 2019;24:33. https://doi. org/10.4103/jrms.JRMS_460_18

3. Stone MJ. The wisdom of Sir William Osler. Am J Cardiol. 1995;75:269-76. https://doi. org/10.1016/0002-9149(95)80034-P

4. Sandler G. The importance of the history in the medical clinic and the cost of unnecessary tests. Am Heart J. 1980;100(6 Pt 1):928-31. https://doi.org/10.1016/00028703(80)90076-9

5. Peyton J. Teaching and learning in medical practice. UK: Silver Birches; 1998.

6. Alguire P, DeWitt D, Pinsky L, Ferenchick G. Teaching in your office. Philadelphia: American College of Physicians; 2008.

7. Dent J, Harden R. A practical guide for medical teachers. 3rd ed. Edinburgh: Churchill Livingstone Elsevier; 2009.

8. Rubenstein W, Talbot Y. Medical teaching in ambulatory care. Toronto: University of Toronto Press; 2013. https://doi. org/10.3138/9781442662339

9. Malaysian Communications and Multimedia Commission. Internet user survey statistical brief number twenty-three. Selangor: Malaysian Communications and Multimedia Commission; 2018. [cited 5 April 2020]. Available from: https://www.mcmc.gov.my/ skmmgovmy/media/General/pdf/InternetUsers-Survey-2018.pdf 
10. Gagne RM, Wager WW, Golas KC, Keller JM. Principles of instructional design. 5th ed. California: Wadsworth; 2005. https://doi. org/10.1002/pfi.4140440211

11. Kolb DA. Experiential learning: experience as the source of learning and development (Vol. 1). Englewood Cliffs, NJ: PrenticeHall; 1984.

12. Kutty AS, Joy MM. Can learning be with fun. 2019 [cited 5 April 2020]. Available from: https://www.researchgate. net/publication/330185223_CAN LEARNING_BE_FUN

13. Gobet F, Lane PCR. Chunking mechanisms and learning. In: Seel NM, editor. Encyclopedia of the sciences of learning. Springer, Boston, MA; 2012. https://doi. org/10.1007/978-1-4419-1428-6_1731
14. Billett S. Realising the educational worth of integrating work experiences in higher education. Studies in Higher Education. 2009;34(7):827-43. https://doi. org/10.1080/03075070802706561

15. Heyer R. Learning through reflection: the critical role of reflection in workbased learning. Journal of Work-Applied Management. 2015;7(1):15-27. https://doi. org/ 10.1108/ JWAM-10-2015-003.

16. Barrows HS, Feltovich PS. The clinical reasoning process. Med Educ. 1987;21:86-91. https://doi. org/10.1111/j.1365-2923.1987.tb00671.x

17. Kassirer JP. Teaching clinical medicine by iterative hypothesis testing: let's preach what we practice. $\mathrm{N}$ Engl J Med. 1983;309(15):921-3. https://doi. org/10.1056/NEJM198310133091511 